\title{
El último aurresku. Género, danza y nacionalismo vasco a comienzos del siglo $\mathrm{XX}^{1}$ The last Aurresku. Gender, Dance and Basque Nationalism at the Beginning of the 20th Century
}

\author{
Oier Araolaza Arrieta \\ Universidad del País Vasco / Euskal Herriko Unibertsitatea \\ oier@dantzan.com \\ ORCID: 0000-0002-5670-6374
}

Recibido: 11-3-2018

Aceptado: 14-5-2018

Cómo citar este artículo / Citation: ARAOLAZA ARRIETA, Oier (2018). El último aurresku. Género, danza y nacionalismo vasco a comienzos del siglo XX. Pasado y Memoria. Revista de Historia Contemporánea, 17, pp. 235-257.

https://doi.org/10.14198/PASADO2018.17.09

\section{Resumen}

Este artículo aborda el proceso de creación de la tradición del aurresku en la primera parte del siglo XX mediante el cual se excluyó a las mujeres de la participación en la principal danza protocolaria vasca. Las visiones de género del nacionalismo vasco se proyectaron también en la danza popular invisibilizando a las mujeres primero y reproduciendo después el esquema de 'binarismo' de género que caracterizó a las culturas políticas de los años veinte y treinta. La aparición de una película de 1921 que muestra un aurresku protagonizado por mujeres contribuye a visibilizar una actividad que persistió a pesar de los procesos de exclusión existentes Los testimonios de aurreskus interpretados por mujeres evidencian una actividad que los folcloristas negaron.

\footnotetext{
${ }^{1}$ Este artículo forma parte de un proyecto de investigación para tesis doctoral que estoy realizando con una beca de la cátedra Mikel Laboa de la Universidad del País Vasco / Euskal Herriko Unibertsitatea. Debo a las directoras de tesis Leire Ituarte y Nerea Aresti la generosa aportación de referencias y de sugerencias interpretativas que han contribuido sustancialmente a la elaboración del presente trabajo.
} 
Se creó y recreó tradición, integrando y reproduciendo a través de la danza los marcos de actuación, significado y representación asignados a las mujeres por el nacionalismo vasco de principios del siglo XX.

Palabras clave: Género. Danza. Nacionalismo. Invención de la tradición. 'Binarismo' sexual.

\begin{abstract}
This article examines the process leading to the creation of the Aurresku tradition, by which women were excluded from the main Basque dance, carried out at the beginning of the 20th century. Basque nationalism gender views were projected to folk dance, making women invisible first and then reproducing the binary gender that characterized the gender views of political cultures during the twenties and the thirties. The finding of a film recorded in 1921 that shows an Aurresku starring women contributes to the visibility of an activity that persisted despite the ongoing exclusion processes. Attested Aurreskus danced by women bear witness to an activity denied by folklorists. Tradition was created and recreated by integrating and reproducing through dance the frameworks of action, meaning and representation assigned to women by the Basque nationalism of the early twentieth century.
\end{abstract}

Keywords: Gende. Nationalism. Dance. Invention of tradition. Binary gender.

\title{
1. Introducción
}

El hallazgo de una filmación inédita de 1921 que muestra a un grupo de veinticuatro mujeres ${ }^{2}$ interpretando la danza denominada aurresku en la localidad vasca de Santurtzi (Bizkaia) ha verificado audiovisualmente lo que a través de documentación escrita y fotográfica ya se venía señalando: que la participación exclusiva de los hombres en danza tradicional vasca en general y la de su danza más identificativa en particular - el citado aurresku- es producto de un proceso de construcción cultural (Hobsbawm \& Ranger, 1983) que ha omitido la participación histórica de las mujeres. Esta construcción habría sido convertida en tradición inmemorial a través de su naturalización en la danza y desde la danza ${ }^{3}$, de las visiones de género de las culturas políticas contemporáneas. Estas culturas políticas se apoyan sobre "determinadas compren-

${ }^{2}$ La grabación de la película en 1921 fue un encargo de Ildefonso Arrola Aqueche, alcalde en funciones de Santurtzi en la fecha y conservado por él mismo en primera instancia y despúes por su hijo Ildefonso Arrola Elias. La película se publicó en internet el 23 de febrero de 2016, en la web Dantzan.eus (2016) y el video se acompañó con un estudio introductorio realizado por Emilio Xabier Dueñas (2016).

${ }^{3}$ Asegura Judith Lynne Hanna (1987: 4) que "la danza refleja y a su vez influye en los patrones de conducta social", y es que como ha escrito Silvia Citro (2012: 13), la danza es también "un modo de ser y actuar en el mundo que tiene importantes consecuencias en la vida social, las relaciones intersubjetivas y las experiencias" del conjunto de la sociedad. 
siones de la diferencia sexual" que Nerea Aresti (2014: 282) ha identificado como "representaciones del cuerpo nacional que albergan un fuerte contenido de género". Entre éstas se inscriben los nacionalismos, incluido el vasco, que participó activamente en el proceso de reelaboración del folclore (Sánchez Ekiza, 2005) de su país, revelándose como una eficaz herramienta para la imaginación, activación y articulación de una comunidad (Anderson, 2006) en torno al proyecto político. Susan A. Reed (2010) ha constatado que desde finales del siglo XIX y comienzos del XX, con la irrupción de los nacionalismos culturales, la danza ha figurado preeminentemente en la creación de muchas culturas étnicas y nacionales.

Debido al valor simbólico y la capacidad de aglutinar identidades que se reconocen a la danza por parte del romanticismo y del nacionalismo, ambos movimientos contribuyeron a la reelaboración del folclore (Bauman, 1992: 38) y la danza tradicional incorporando en ellas sus visiones de la masculinidad y de la feminidad. El boomerang funcionó con precisión ${ }^{4}$ al devolver a través de la danza la imagen de una comunidad de marcada y jerarquizada división de género. A través de aquella imagen supuestamente tradicional, la comunidad reproduciría al fin los estereotipos de masculinidad y feminidad que habrían formado parte de su tradición imaginada.

"La mujer no baila en el verdadero sentido de la palabra. Lo hacen los hombres, más especialmente los jóvenes". La sentencia la firmó José Gonzalo Zulaica, más conocido como Aita [Padre] Donostia (1932: 4), sacerdote, músico, compositor y recopilador de canciones y danzas vascas, responsable de una extensa obra sobre el acervo coreográfico y musical vasco. Lo argumentó en una conferencia impartida en 1932 en el Centro de Cultura Femenina de Donostia, en la que añadió que "La mujer asiste al baile para 'ser bailada' [...] para que ante ella muestre el varón sus habilidades", pero que "como danzarina, como elemento activo del baile, la mujer vasca no interviene en él". La negación del Padre Donostia incidía en una falsedad que a fuerza de repetición fue deformando la propia realidad hasta erigirse verdadera (Merton, 1995). El musicólogo Francisco Gascue (1915: 2) ya lo había enunciado veinte años antes: "Las señoras no bailan". Gascue justificaba la discriminación debido a que se bailaba "de acuerdo con las costumbres populares, antiguas".

$\mathrm{Al}$ asegurar que la mujeres vascas no bailaban, Gascue y Donostia se referían específicamente a una danza: el aurresku. Es este un baile interpretado

${ }^{4}$ Utilizamos el termino boomerang en referencia a la profecía autocumplida de Merton (1995: 506-507) que parte de "una definición falsa de la situación que suscita una conducta nueva, la cual convierte en verdadero el concepto originariamente falso". 
por un grupo de personas que forman una cadeneta con las manos entrelazadas y marchan en círculo abierto, en sentido contrario a las agujas del reloj, y guiados por el primero de la fila. Este primer bailarín es el que da nombre a la danza, ya que aurresku en euskera significa 'mano delantera' y se refiere al que ocupa la posición delantera en la danza de manos. Efectivamente fue en un trabajo sobre el aurresku donde Gascue (1915: 2) aseguró que "en este baile, los hombres son los únicos que bailan". Pero la justificación de la desigualdad de género en la danza vasca iba más allá del aurresku, ya que el Padre Donostia (1932: 4) consideraba que "nuestra danza es gimnástica, fuerte, impropia de la delicadeza femenina". Otro sacerdote, lingüista y también gran recopilador de canciones y músicas vascas, Resurrección María de Azkue (1922), dedicó 200 páginas de su cancionero a la danza, en las que, sin embargo, no hay noticias de aurreskus bailados por mujeres y al referirse al mismo lo define como danza interpretada "por conjunto de hombres" (1922: 264). El aurresku, una de las danzas más representativas del sistema coreográfico vasco, se mostraba por tanto como un baile inequívocamente masculino. De esta manera, se daba continuidad a la vocación exclusivista de la primera etapa del nacionalismo, en la que las mujeres quedaron fuera de toda manifestación pública. Pero también se abría la puerta a la incorporación sexuada (Aresti, 2014) de las mujeres al movimiento nacionalista que se impulsó en los años 20 y 30. Ellas tenían lugar en el nacionalismo pero como sexo femenino, en sus espacios y actividades. Lo mismo en el baile, podían bailar siempre y cuando lo hicieran como mujeres y uniformadas como mujeres.

Los ideales románticos y el nacionalismo vasco convergieron en el interés por reproducir el aurresku como danza protocolaria y festiva. El aurresku de autoridades constituyó uno de los platos habituales de las Fiestas Euskaras ${ }^{6}$ en su etapa de comienzo del XX. Organizadores, autoridades civiles y mecenas participaban en una danza que les permitía mostrarse en público para disfrutar del agasajo de las clases populares en agradecimiento a su desinteresada labor como salvaguardas de las tradiciones vascas. Además, la danza, junto a la música y el teatro se manifestaron como poderosas herramientas para activar emociones a las que se asoció el sentimiento nacionalista (Díaz Freire, 2001: 79-80).

${ }^{5}$ Además de aurresku, esta danza se conoce con diferentes nombres entre los que se encuentran soka-dantza o dantza-soka [baile en cuerda], zortziko [de ocho] y esku-dantza [baile de manos].

${ }^{6}$ Las Fiestas Euskaras inspiradas en los Juegos Florales que impulsó el filantropo vascófilo Antoine Thompson de Abbadie en la segunda mitad del siglo XIX pusieron el foco en algunas manifestaciones folclóricas, como la ezpata-dantza, los tamborileros o el aurres$k u$, que más tarde el movimiento nacionalista integró en su propia estructura ritual. 
La oposición entre las edificantes y castas danzas vascas como el baile al suelto, el aurresku y la ezpata-dantza, en contraposición al inmoral y lujurioso baile agarrado identificado como español constituye un terreno de juego crucial en la construcción del ideario nacionalista de Sabino Arana (1897, 1980b; Guezala, s. f.). Todo ello interiorizado y exteriorizado a través del cuerpo, ese "cuerpo nacional vasco" que Aresti (2016: 121) ha observado que se define "en términos culturales más que biológicos, en oposición al "cuerpo español" y que en palabras de Díaz Freire (2001: 81) "es el receptor y el generador de las emociones que caracterizan al nacionalismo".

Este primer nacionalismo vasco, articulado en torno a la doctrina cristiana, contribuyó a la identificación del aurresku como la auténtica danza vasca ${ }^{7}$, eso sí, en su versión más casta y decente: la masculina. Alejando el siempre pecaminoso contacto entre los sexos, se imponía el criterio moral católico y se evitaban los espacios mixtos y el contacto de los cuerpos. De la misma manera que en las románticas Fiestas Euskaras, también en las ceremonias del primer periodo del Partido Nacionalista Vasco ${ }^{8}$ el aurresku fue una recurrida pieza simbólica. La función que en estos momentos asignan los ideólogos nacionalistas al aurresku se percibe en este enunciado publicado en su rotativa Patria ${ }^{9}$ con motivo de la festividad de San Ignacio de 1904: "El aurresku es el reflejo del orden privado; la exaltación y respeto a la mujer y la castidad de hogar". Sabino Arana impregnó a este primer nacionalismo vasco de una visión de género que emanaba de la misoginia prerromántica (Aresti, 2014: 284) y en el que la diferencia de género era concebida en términos de jerarquía entre los sexos. Las mujeres no sólo fueron excluidas del proyecto político en esta primera etapa, sino que también se les denegó el acceso a las principales herramientas de propaganda como el teatro y la danza.

Los cambios que acompañaron el contexto de la Primera Guerra Mundial afectaron también al nacionalismo vasco y su visión de la diferencia sexual.

${ }^{7}$ Durante los siglos XVIII y XIX, el aurresku o soka-dantza se encontró en el centro de un debate sobre la moralidad en la fiesta y en la danza, en el que se sucedieron misiones, sermones y prohibiciones por parte de la jerarquía eclesiástica que consideraba escandaloso el contacto físico que se producía entre hombres y mujeres en algunas partes del baile. (Bidador, 2005) Eliminados los momentos más delicados de la danza y con la introducción del pañuelo para evitar el contacto entre los participantes de diferente sexo, el aurresku llegó al siglo XX desprovisto de contactos físicos y apto para ser consumido incluso por la más estricta moral cristiana. (Sánchez Ekiza, 2005)

${ }^{8}$ Socios fundadores del Euskeldun Batzokija bailaron el aurresku en 1894 en la fiesta de inauguración de la primera sede del partido en Arrigorriaga, y también en 1895, en la fiesta de aniversario de su fundación. (Arana Goiri, 1980a: 322 y 653)

${ }^{9}$ El festival (1904, julio 24). Patria. Jaun-goikua eta lagi-za a, p. 1. 
Junto a la noción jerárquica del género comenzó a manifestarse una visión más esencializada y basada en la idea de complementariedad (Aresti, 2014). Se tendió entonces a redefinir el lugar de las mujeres en una nueva, recreada tradición vasca, y se trató de acotar qué y cómo debían bailar. En este nuevo contexto, el aurresku se siguió bailando en los principales actos del partido, y fue también la danza escogida por los dirigentes nacionalistas para celebrar protocolariamente el primer día de la patria vasca, el Aberri Eguna de 1932. En definitiva, el carácter supuestamente masculino de la danza se confirmaba cada vez que se interpretaba exclusivamente por hombres.

Por una u otra razón, desde una visión más performativa y jerárquica del género, o desde su comprensión en términos de esencias y complementariedad, el aurresku fue definido como masculino durante todo el siglo XX. A lo largo de la centuria, folcloristas, músicos y maestros de danza han difundido una visión mutilada del aurresku como danza exclusivamente masculina. Esta sistemática negación de la participación de las mujeres en la danza más identificativa del folclore vasco ha calado con tal profundidad en el imaginario colectivo, que aunque hace dos décadas que se están aportando datos que lo desmienten, todavía se sigue reproduciendo este juicio normativo. Una precisa explicación sobre la manera de bailar el aurresku publicada en 1966 advierte que las mujeres "en el aurresku propiamente dicho no hacen más que recibir el homenaje de los bailarines y formar la cuerda y no bailan durante él". En un trabajo publicado en 2008 en una revista científica sobre folklore se asegura (San Sebastián, 2008: 98) que las danzas "en toda la cultura vasca, han sido y son patrimonio de los hombres", y especifica que "todos los bailes públicos y protocolarios los ejecutaban hombres". La concepción sexista del aurres$k u$ se sigue reproduciendo en 2018 tanto en artículos de prensa ${ }^{10}$ como en la wikipedia, en la que se afirma ${ }^{11}$ que se trata de una danza que "se compone exclusivamente de hombres".

\section{El aurresku y las mujeres en el siglo XIX}

La falsedad de la asunción de que eran exclusivamente los hombres quienes interpretaban el aurresku en la tradición popular vasca ha sido puesto de manifiesto por varios autores en las últimas dos décadas. Fernando Rojo (1999), Josu Larrinaga (2004), Iñaki Irigoien $(1996,2007)$ y recientemente Emilio

\footnotetext{
El Correo.

${ }^{10}$ Moyano, I. (2018, febrero 13). Antzinako soka-dantzatik, gaur egungo Aurreskura.

${ }^{11}$ Aurresku. (2017, diciembre 2). En Wikipedia, la enciclopedia libre. Recuperado a partir de https://es.wikipedia.org/w/index.php? title=Aurresku\&oldid=103884787
} 
Xabier Dueñas (2017) han demostrado con documentación histórica y etnográfica la participación de las mujeres en esta danza. Afirma Irigoien (2010b) que "en contra de la opinión de muchas personas, las mujeres han bailado y dirigido activamente la Soka Dantza o Aurresku, como se puede demostrar históricamente". Por otro lado, debemos señalar, que por lo menos un autor contemporáneo a Gascue, Donostia y Azkue, trató de poner de relieve la falsedad de lo que estaban enunciando. Se trata del antropólogo Telesforo de Aranzadi, que en 1934 escribió en clara respuesta al Padre Donostia que "antes hubo etxeandre-dantza y neskatxen-esku-dantza"12 y afirmó que "en nuestros tiempos hemos visto aurresku femenino". Este debate ratifica la definición sobre las tradiciones que ha propuesto Virginia Maquieira (1998: 195-196), que las contempla como "procesos activos de ratificación o impugnación cultural de un orden contemporáneo".

El significado político del baile de las mujeres había sido objeto de debate desde mucho tiempo atrás, en polémicas acerca de la articulación entre el género y la pertenencia a una comunidad identitaria. A mediados del siglo XVIII, el Padre Manuel de Larramendi (1985: 274) escribió sobre mujeres que "saben danzar los zortzicos" y que lo hacían "sin indecencia ninguna". Como apologista de las costumbres del país, Larramendi (1985: 275) tomó partido en el debate sobre la moralidad en los bailes ensalzando la decencia de las danzas vascas en oposición a "las otras danzas" que "no son propias de este país, y han venido de fuera, y no tienen los defensivos de nuestras danzas". Como "defensivo" se refería al uso del pañuelo para evitar el pecaminoso contacto físico entre mujeres y hombres en el aurresku. Larramendi (1985: 287) reconocía que era habitual que las mujeres dieran la mano a los hombres en la danza y aunque trató de restarle gravedad, solo reconoció como propia y aprobó para su uso aquella en la que se bailara "con pañuelos y que no se den las manos hombres y mujeres". Larramendi trataba de que prevaleciera una modalidad de la danza, la única que consideraba decente, a la vez que denostaba el resto, cimentando a través de la idealización de las costumbres la invención de la tradición ${ }^{13}$.

12 Son dos aurreskus bailados por mujeres, cuya traducción viene a significar "danza de mujeres casadas y danza de manos de chicas jóvenes" y que describe Juan Ignacio Iztueta en 1824 (1824: 83-86)

${ }^{13}$ Advierte Díaz Freire (2001: 85) que "la idealización que se inicia con la obra de Larramendi es un proceso similar al que se ha definido como de "invención de la tradición". En esta línea, Bakarne Altonaga (2016: 14) ha analizado cómo construye Larramendi el ideal de feminidad en su crónica sobre Gipuzkoa, en un proceso que ha descrito como "fundamentalmente creativo, en el que aspectos vivos de la tradición se trenzaron con elementos mitificadores de los mismos, con el fin de generar la idea de un pasado inalterable al que el presente y el futuro debían corresponder". 
Sorprende la naturalidad con la que se atestiguan danzas protagonizadas por mujeres en los siglos XVIII y XIX, en contraposición a lo que ocurre en el primer tercio del siglo XX, periodo en el que se niega su existencia hasta erradicar su práctica. Altonaga (2016: 18) sugiere que "Larramendi participaba de una visión de las mujeres característica de las sociedades que Thomas Laqueur denominó de sexo-único". En esta visión se advierte la condición performativa del género que ha desenmascarado Butler $(1988,2006)$ y que concibe el cuerpo como un proceso que se construye por medio de prácticas disciplinarias que se reiteran en el tiempo. En esta noción butleriana de performatividad del género, es la práctica reiterada de las normas reguladoras la que materializa el sexo, aunque los cuerpos no siempre obedecen a dicha ley. Así, en tiempos de Larramendi, el sustrato "natural" del género era inestable, y podía mudar por influencia de la conducta (Aresti, 2006: 51). En consecuencia, bailar en público y liderar un aurresku era para las mujeres una demostración de virilidad, un valor que podía, en ocasiones al menos, elevarlas sobre su condición de género: cuanto más y mejor, más se acercaban a la para ellas inalcanzable, debido a su pecado original perfección del sexo único. Altonaga (2016: 37) ha explicado que Larramendi defendía la participación de las mujeres, incluso en el baile, porque el jesuita "anteponía la calidad moral de las guipuzcoanas a sus prejuicios misóginos". En la visión de género que construye Larramendi prevalece la superioridad moral y física que atribuye al particularismo guipuzcoano (Altonaga, 2016: 41) sobre la condición femenina. Aprueba y defiende la participación en la danza de las mujeres guipuzcoanas, porque son más guipuzcoanas que mujeres, de manera que interpretar danzas del país reafirma su moralidad y contribuye a su virilidad.

Desde finales del siglo XVIII y durante el siglo XIX los testimonios ${ }^{14}$ de soka-dantzas, aurreskus o zortzikos interpretados por mujeres permiten vislumbrar una práctica de cierta frecuencia. Debido a la contundencia de la negación y su perseverancia en el tiempo, hemos considerado pertinente reseñar en las siguientes líneas testimonios que demuestran que la interpretación del aurresku por parte de mujeres ha sido una evidencia documentalmente verificable.

El diplomático francés Jean-François Peyron (1782) fue testigo a su paso por Vitoria en 1778 de una soka-dantza en la que hombres y mujeres formaban sus propias cuerdas de baile saliendo ambas a la plaza al unísono y bailando paralelamente antes de acabar fusionandose en una única cadeneta. En el ocaso del siglo XVIII, el viajero y escritor alemán Christian August Fischer

${ }^{14}$ Debemos a Iñaki Irigoien $(1985,2006,2010 b)$ el conocimiento de varios de los testimonios que se citan a continuación. 
(1802: 90) fue testigo en Bilbao de un aurresku en el que "una cuerda de jóvenes mujeres tomándose unas a otras de la mano siguen en fila recta a la primera, quien de cuando en cuando se gira hacia atrás y da pasos hacia el resto". Pocos años después, en 1813, durante la Guerra de la Independencia Española, el viajero y escritor inglés Edward H. Locker (Santoyo, 1978) observó en Vitoria "un grupo de hermosas jóvenes bailando por la calle al son de la gaita y el tambor".

El escritor ilustrado Juan Antonio Zamacola (1828: 311) aseguró que la "pasión dominante" de las mujeres de principios del siglo XIX era "la carricadanza o bayle público Bizcayno". Lo corroboró Juan Ignacio Iztueta (1824), que publicó un libro sobre las danzas de la provincia de Guipuzcoa en el que entre diferentes modalidades de aurreskus ofrece la descripción de dos en las que las protagonistas son féminas ${ }^{15}$. Explica Iztueta que es costumbre que los aurreskus de mujeres casadas se celebren el cuarto y último día de las fiestas patronales. En cuanto a las jóvenes solteras, según Iztueta (1824: 85), la voluntad de mostrar su preparación y habilidad para la danza es suficiente para que una joven bailarina abra el baile y dé comienzo a un aurresku. Una vez la cuerda de baile se sitúa en la plaza, la primera bailarina puede interpretar tantos zortzikos y melodías viejas como sepa. Iztueta (1824: 107) nombra a una bailarina de Durango, de sobrenombre Pontxera, que en 1806 bailó brillantemente en la plaza de Azpeitia interpretando viejas melodías.

En el contexto de la primera guerra carlista (1833-1840), el periodista inglés Edward Bell Stephens (1837: 163-165), desplazado a las provincias vascas para hacer seguimiento de la contienda, describió una fiesta en Iurreta, en la que "una larga fila de jóvenes mujeres" abrieron la danza, a la que después incorporaron a los varones que se encontraban en la plaza, incluidos soldados. En Deusto (Bizkaia) una crónica de 1846 (Irigoien, 1996: 339) da cuenta de la "antiquísima costumbre que después de misa mayor bailen un zortzico las mujeres casadas, en el que se da el primer puesto o sea el aurrescu a la mejor danzarina del pueblo". Un año más tarde, en 1847, en la localidad costera de Bermeo, el político en las Cortes Salustiano de Olózaga fue recibido ${ }^{16}$ con una serie de aurreskus entre los que destaca el bailado por "señoritas de la villa, en el que sacaron" para ser agasajado al propio diputado. En la siguien-

\footnotetext{
${ }^{15}$ Se trata de etxe-andre dantza [danza de amas de casa] y esku-dantza neskatxena [baile de manos de chicas jóvenes] que conocían perfectamente Gascue, Donostia y Azkue, y que Aranzadi sacó a la palestra como hemos citado anteriormente. (Iztueta Echeverría, 1824)

${ }^{16}$ Corresponsal de Bermeo. (1847, agosto 18). Nuestro corresponsal de Bermeo nos dá cuenta del recibimiento que hizo aquel pueblo al señor Olózaga y á su familia. El Clamor público, p. 3.
} 
te década, las crónicas de sociedad de la burguesía bilbaína que reflejan las recopilaciones epistolares de Juan Carlos Gortazar (1920: 252) dan noticia de un aurresku en Portugalete en 1857, "el cual lo hizo un día primorosamente Antonia la modista, mujer de Emilio". El mismo año en Lekeitio, el historiador Antonio Cavanilles (1858: 7) afirma que mientras "Juegan pelota los mozos; bailan las mozas al son del tamboril".

Durante el siglo XIX se suceden múltiples cambios sociales, se producen tensiones entre concepciones ilustradas y resistencias tradicionalistas, el romanticismo se enfrenta al clasicismo (Tortajada, 2004: 45) cuestionando la preeminencia de la forma sobre el contenido, y se van modificando las visiones de género que configuran las definiciones de masculinidad y feminidad. Con el romanticismo, en el arte occidental en general y en la danza en particular, se representa un modelo de feminidad más esencializado, los hombres comienzan a abandonar la danza escénica (Albizu, 2017: 63-78), dejando de representar los roles femeninos en primera instancia ${ }^{17}$, e incluso los roles masculinos pasarán a ser representados por mujeres travestidas (Nordera, 2011: 131).

En 1877, 71 años después de la exhibición de Pontxera en Azpeitia, la misma plaza es escenario de un aurresku de muchachas, con motivo de las fiestas patronales. "Las danzarinas se presentan tocadas de boina roja y unidas por las manos". Lo narra el escritor francés Louis Lucien Lande (1931: 89) en su crónica de la visita realizada al País Vasco al finalizar la tercera guerra carlista, observando que, aunque interpretado por mujeres, "todo se produce como el aurresku ordinario". El escritor francés añade un comentario que permite vislumbrar el proceso de categorización por género que se está impulsando y la preeminencia masculina con la que ya cuenta valorativamente la danza y que va a ser reforzada en las siguientes décadas: "Sea como fuere me gusta más el aurresku en su pureza, bailado como debe ser, por hombres".

Las estancias de verano estival en San Sebastián de la reina regente (18851902) María Cristina Habsburgo-Lorena le permitieron ser testigo de diversas manifestaciones populares de baile entre las que podemos destacar dos aurreskus protagonizados por mujeres. En 1887, una crónica periodística ${ }^{18}$ anotaba que "S. M. se ha manifestado satisfecha del aurresku" que "por indicación

${ }^{17}$ Desde el Renacimiento ha sido frecuente la interpretación de roles femeninos en teatro y danza por hombres jóvenes: "doce caballeros vestidos de ninfas" y "cuatro adolescentes vestidos de amazonas" participaron, por ejemplo, en la festa da ballo representanda en Milán en 1599. (Pontremoli, 2011: 60)

${ }^{18}$ De nuestro servicio particular. (1887, agosto 30). La Corte en San Sebastián. La Época, 12.606, 2. 
suya inició el baile la hija del Alcalde de San Sebastián". Dos años después, fue un grupo de bañeras, mujeres encargadas de ayudar a los veraneantes a disfrutar del agua del mar sin peligros, las que agasajaron a la reina con la interpretación del aurresku en la misma playa, según la crónica ${ }^{19}$ del Dr. Garci-Díaz: “... al son del tamboril, aparecieron las bañeras, que, sobre la arena mullida, zapatearon de lo lindo, desafiando el cierzo y la lluvia". La afición de las bañeras a bailar el aurresku se confirma en Deba, otra localidad costera vasca que gozó de gran predicamento por parte de los veraneantes del final del XIX. En 1890, la crónica periodística ${ }^{20}$ da cuenta de un aurresku en Deba en el que "gentiles muchachas que movían el cuerpo con donaire y que llevaban a la cabeza las boinas de sus galanes bailaban la danza popular". En definitiva, son numerosas y variadas las fuentes que atestiguan la práctica de aurreskus protagonizados por mujeres a lo largo del siglo XIX.

\section{Siglo XX. Los últimos aurreskus de las mujeres}

Los años previos a las tajantes negaciones de Gascue (1915) y el P. Donostia (1932) sobre la participación de la mujeres en el aurresku siguieron contradiciendo las aseveraciones de los musicólogos. Emilio Xabier Dueñas (2018) ha documentado un buen número de aurreskus liderados y bailados por mujeres en el final del siglo XIX y el comienzo del XX en Gordejuela (1877), Deba (1879), Gorliz (1882), Algorta (1884), Bermeo (1885), Lekeitio (1905), Etxebarri (1907), Eibar (1909), Areatza (1912) y Abanto y Ciérvana (1914), entre otros. Los ejemplos proliferan de hecho en distintos pueblos, en actos festivos o conmemorativos, en lo que fue, a todas luces, una práctica relativamente común. En 1897 en fiestas de Oiartzun ${ }^{21}$ "el aurresku fue bailado por varias distinguidas señoritas" y no se trataba de un acto clandestino que pudiera pasar desapercibido, ya que "el obispo de Vitoria presenció la fiesta desde un balcón de la Casa Consistorial". En los actos organizados con motivo de la reapertura del Santuario de Estíbaliz (Álava) en 1906, "las Autoridades organizaron un aurresku que se bailó por varias damas con la mayor solemnidad y clasicismo".(Antequera, 2016: 87; Izarra, 1921: 94)

Entre las diferentes modalidades de concursos de aurresku que se celebran en la primera parte del siglo XX, fueron frecuentes los dirigidos a aurreskula-

${ }^{19}$ DOCTOR GARCI-DÍAZ (1889, octubre 4). Aurresku en la playa. La Época, 13.333, 2.

${ }^{20}$ Baños y bañistas. Deva. Zumaya. (1890, agosto 23). El Liberal, p. 1.

${ }^{21}$ DE NUESTRO CORRESPONSAL (1897, julio 5). Las fiestas en Oyarzun. La Época, $16.913,1$. 
ris de edad avanzada, y aunque en menor medida, también se celebraban concursos de aurresku de mujeres. En Begoña, en 1905, se celebró un concurso ${ }^{22}$ para "ancianas mayores de 59 años que mejor bailen nuestro baile nacional, el aurresku", y también hay constancia (Berguices, 2016: 275) de concursos femeninos de aurresku en Erandio en 1910 y Basauri en 1916. El aurresku también tuvo su presencia en el teatro. En la programación teatral de varietés madrileña, en 1916, "La Bilbainita" entusiasmó "a los espectadores bailando el aurresku" (Acuña, 1916: 6) en el teatro Romea.

Desde los primeros tratados de danza del siglo XV a los complejos sistemas de notación de Rudolf Laban, o el ideado por Joan y Rudolf Benesh, el interés por describir y documentar la danza había impulsado el desarrollo de varios sistemas de escritura y registro gráfico del arte coreológico. Con la invención del cinematógrafo al final del siglo XIX en primer lugar, y los diversos formatos de grabación audiovisual que lo han seguido durante el siglo XX y XXI, el uso de los sistemas de notación de danza ha quedado circunscrito al ámbito de la investigación coreológica (Álvarez, 2006). Las menciones y descripciones literarias, periodísticas y musicológicas sobre el aurresku durante los siglos XIX y XX son numerosas (Castell, 1897; Gascue, 1916), pero carecemos de notaciones coreográficas. Las primeras filmaciones de aurreskus que conocemos datan de la tercera década del siglo XX. En 1923 Manuel Intxausti (Larronde, 1998) comenzó una serie de filmaciones de manifestaciones culturales vascas, entre las que se pueden mencionar la gizon-dantza o aurresku de autoridades en Donostia, la danza de espadas y su aurresku en Zumarraga, y el concurso de aurreskularis [danzarines de aurresku] celebrado en Donostia con motivo de las Fiestas Vascas de 1923. En 1926 otros pioneros de la cinematografía vasca, los hermanos Victor y Mauro Azkona ${ }^{23}$, filmaron un concurso de aurresku en Bergara. Del año anterior, de 1925, contamos con dos filmaciones de aurresku, uno en Oñate ${ }^{24}$ con imágenes de por lo menos dos aurreskus, el primero de paisano y el segundo bailado por los dantzaris que interpretan las danzas rituales de la festival del Corpus Christi, y el otro en Areatza ${ }^{25}$, en una singular cuerda conformada por mujeres y encabezada por un hombre, todos de avanzada edad.

\footnotetext{
${ }^{22}$ Patria. (1905, agosto 5). Los vascos en el día de San Ignacio. Patria. Jaungoikua eta lagizarra, 106(III. urtia), 1-4.

${ }^{23}$ AZKONA, Mauro; AZKONA, Victor (1926). Bergara 1926 Uztai handi eta aurresku txapelketa. Bergara. <https://dantzan.eus/bideoak/bergara-1926-02>.

${ }^{24}$ Oñati 1925: aurreskua eta Korpus dantzak. <https://dantzan.eus/bideoak/onati-1925>.

${ }_{25}$ Areatza: Aurreskua 1925. (1925). Areatza. <https://dantzan.eus/bideoak/areatza-au rreskua-1925>.
} 


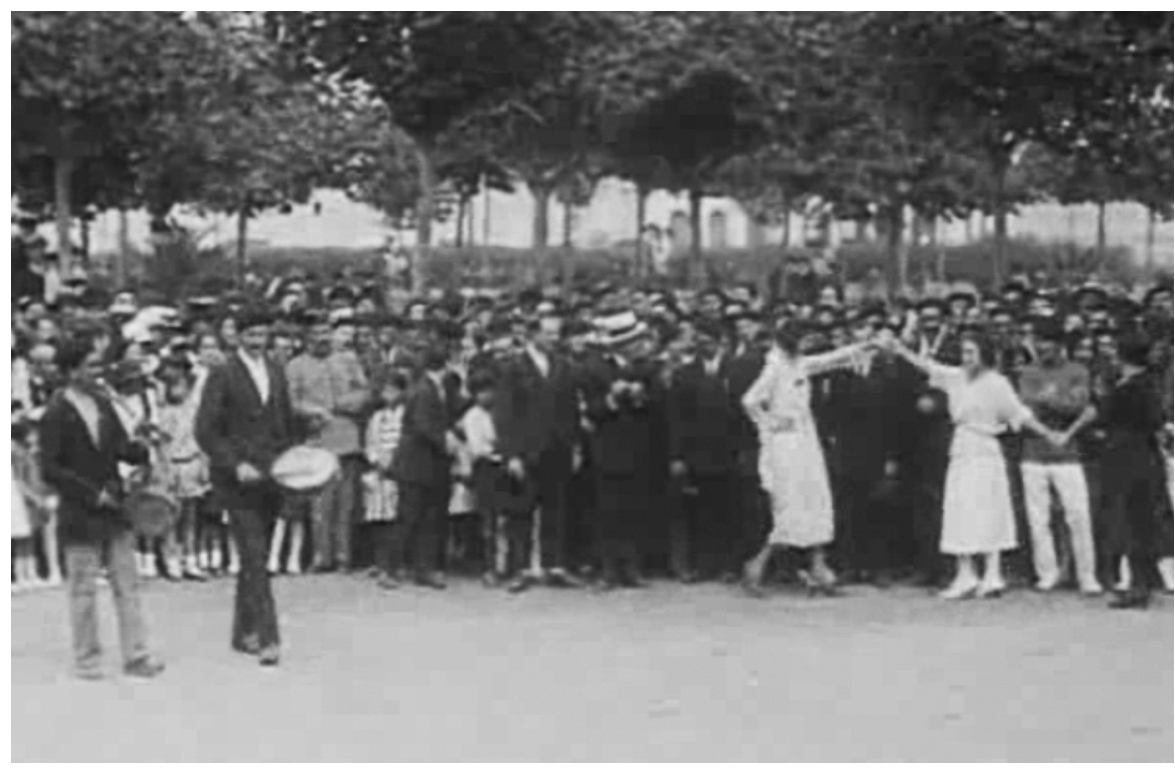

Fotograma de la filmación del aurresku protagonizado por mujeres en Santurtzi en 1921

La reciente aparición de una filmación fechada en 1921, en la que se puede observar a un grupo de mujeres bailando el aurresku en Santurtzi supone, por tanto, el más antiguo documento audiovisual del aurresku, independientemente de que los intérpretes sean hombres o mujeres, además de poner en imagen una actividad -el aurresku interpretado por mujeres- del que se ha negado su propia existencia.

La fiesta de celebración de la victoria del bote local en las regatas de traineras y el agasajo a la tripulación victoriosa fue el contexto en el que tuvo lugar el aurresku protagonizado por mujeres en Santurtzi en 1921. El organizador de las regatas y patrocinador de la embarcación santurtziarra, el alcalde en funciones Ildefonso Arrola, fue a su vez el impulsor de las fiestas conmemorativas y el que contrató al equipo de filmación que registró audiovisualmente los actos del programa de festejos (Dueñas, 2016, 2017). Veinticuatro jóvenes muchachas de Santurtzi bailaron el aurresku, al que invitaron a unirse a los diecisiete remeros y a siete miembros de la corporación municipal.

La película completa tiene una duración de 7 minutos y 24 segundos, incluyendo imágenes del Puente Bizkaia, de la procesión y del oficio religioso que se celebraron antes del baile. La parte de la danza (dantzan.eus, 2016) tiene una duración de 2 minutos y 19 segundos. En ella están presentes un txistu- 
lari ${ }^{26}$ y un tamborrero, que aparecen interpretando la música con la que se baila el aurresku, aunque la cinta carece de sonido. En el filme se pueden observar secuencias de diferentes partes que componen el aurresku de cuerda en el siglo XXI, y que coinciden con las descripciones literarias (Antequera Chávez, 2016; Díaz de Arcaya, 1906; Gascue, 1916) de principios del siglo XX: 1) La danza que realizan frente a las autoridades las dos bailarinas solistas, denominadas aurresku y atzesku, e interpetadas por Juana Agirre y María Fernández. 2) Las mujeres aparecen caminando una tras otra, con las manos entrelazadas formando una cuerda que lidera la primera mano o aurreskulari que baila a la vez que avanza en el círculo en sentido inverso a las agujas del reloj. 3) Dos danzarinas acompañan al patrón de la embarcación a un lateral donde la atzeskulari baila frente a él. 4) Remeros y miembros de la corporación municipal entran en la cuerda, alternándose con las mujeres y dándose las manos con ellas. 5) La aurreskulari y la atzeskulari bailan unidas a la cadeneta de la que ya forman parte hombres y mujeres, una cuerda que sigue avanzando en el círculo, ya que las bailarinas solistas avanzan bailando mientras el resto camina. 6) Las dos danzarinas solistas sueltan sus manos, se cruzan entre ellas, y bailan frente a la otra pareja. 7) Todas las mujeres y los hombres que participan en el baile, bailan un pasacalle sin soltarse de las manos, y pasando por debajo de las manos que unen el aurresku y su pareja en primera instancia y del atzesku y su pareja en segunda. 8) Se sueltan las manos, la cuerda se deshace, y por parejas o cuartetos, bailan al suelto, lo que puede ser el fandango y/o arin-arin con el que se completaba el aurresku.

Una fotografía tomada en 1922 en Bermeo muestra (Legarreta, 2008: 126) un grupo de mujeres, en fila, con sus manos entrelazadas, bailando el aurres$k u$ en las fiestas de la localidad. Felipe Amutxastegi e Iñaki Irigoien (2010a) han documentado, a través de testimonios orales, que en ese primer tercio del siglo XX las mujeres de Lekeitio bailaban el aurresku. Irigoien (2010b: 106) muestra su sorpresa por el hecho de que Resurrección María de Azkue, natural de Lekeitio y recopilador y autor de una extensísima obra de folclore musical, no hubiera prestado atención al aurresku de mujeres de su propia localidad. Azkue publicó ${ }^{27}$ la melodía del aurresku de mujeres de Lekeitio en 1897 con un nombre inequívoco: Neska-dantzea [danza de muchachas]. Pero después no lo incluyó ni lo citó en su gran trabajo de recopilación, el Cancionero popular

\footnotetext{
${ }^{26}$ Músico tradicional vasco tañedor de txistu, flauta de pico de una sola mano acompañado de un tamboril.

${ }^{27}$ AZKUE, Resurrección María de (1897, noviembre 18). Neska-dantzea. Euskalzale, 1 urtea (47), 376.
} 


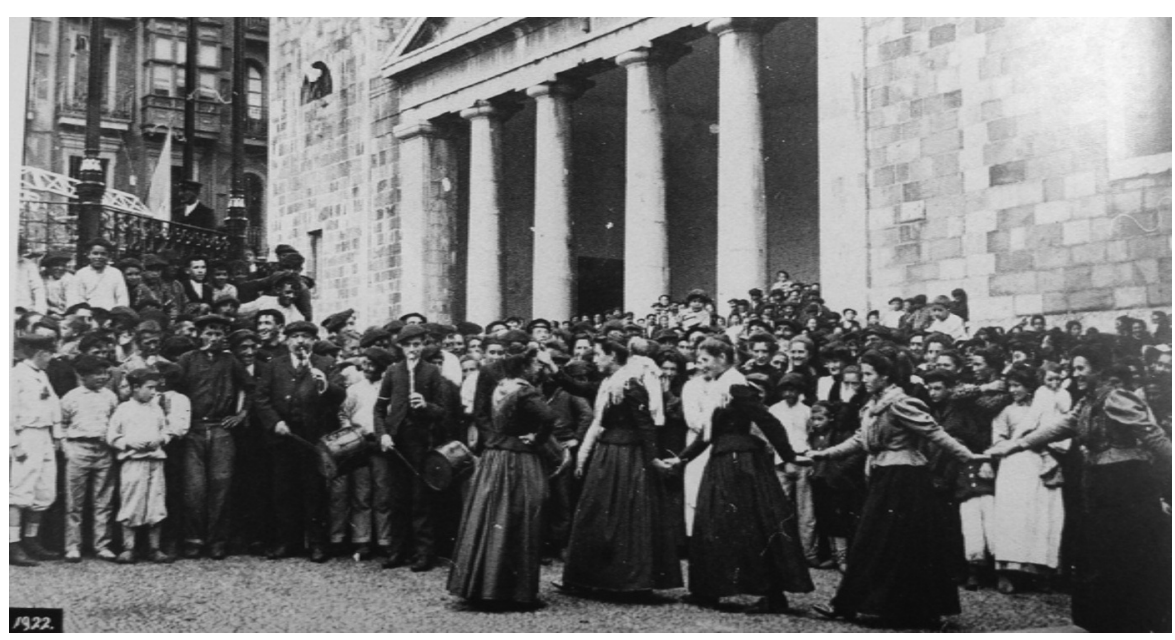

Mujeres de Bermeo bailando el aurresku en 1922

vasco (1922), una obra monumental, con más de 1000 canciones, de las cuales cerca de 200 son danzas, pero entre las que no se encuentra ni la que bailaban las mujeres en su localidad natal, ni ningún otro aurresku protagonizado por el género femenino.

Otros dos clérigos, Policarpo de Larrañaga y José Gonzalo Zulaika “Aita Donostia" trabajaron intensamente en las décadas de 1920 y 1930 en labores de documentación de folclore, recopilación etnográfica y en la puesta en marcha y dirección de grupos de canto, teatro y danza. En sus trabajos hay referencias de danzas y aurreskus interpretadas por mujeres. Larrañaga (1930: 15) cita al inglés Bowles que vio muchas veces en Bilbao mujeres "bailando por las calles al son del tamboril entrelazadas de las manos unas con otras" y también se hace eco (1930: 58) del testimonio de Humboldt, quien habla de muchachas que bailaban en la calles de Durango en fila, "mandada por la de más edad y luego las otras en hilera". El Padre Donostia (1983: 496-497) dio a conocer la descripción del aurresku que observó Edward Bell Stephens en 1837 en Iurreta en el que bailó "una larga hilera de muchachas (...) trabadas las manos, dirigidas por la que iba en cabeza".

El nacionalismo musical (Sánchez Ekiza, 2005) y coreográfico de la primera parte del siglo XX, de la que Azkue, Larrañaga y Donostia, entre otros, constituyeron la punta de lanza, fue fiel a la concepción católica del primer nacionalismo en su intervención en el ámbito cultural. En consonancia con la identificación del buen vasco con la ejemplaridad religiosa (Altuna, 2006), 
actuaron con la presunción de que el verdadero (Schechner, 1990; Reed, 2012) folclore vasco era el que mejor representaba las cualidades morales de la fe cristiana. Partiendo de la asociación de categorías vasco = moral en oposición a español = inmoral, se clasificaron danzas e instrumentos musicales, identificando el txistu y el tamboril y sus danzas como la ezpata-dantza y el aurresku como modélicos castos y auténticos vascos, y las charangas y acordeones y sus pecaminosos bailes agarrados como inmorales y extranjeros. Larrañaga (1930: 73) se felicita por el empuje demostrado por la Asociación de Txistularis en "una cruzada en pro de la moralidad pública de nuestras seculares costumbres y entidades oficiales. En ello va no tan sólo el altísimo interés moral de todo un pueblo, ya que también reporta beneficios materiales al País".

Para transmitir y difundir la mejor versión del folclore vasco, Azkue (1922: $346,270,333)$ reconoce que no dudaron en aplicar filtros en la recogida, descartó variantes "por insulsas", modificó lo que consideró incorrecto y completó a su criterio las lagunas de sus informantes. Así, a pesar de que ellos mismos dieron cuenta de testimonios sobre mujeres bailando el aurresku, y a pesar de la evidencia de que las mujeres bailaban el aurresku en su propia época, fueron capaces de no ver el elefante en la habitación.

\section{Conclusiones. Danzas para hombres y danzas para mujeres}

En las décadas de 1920 y 1930 las mujeres fueron entrando gradualmente en el espacio público, obligando a los movimientos políticos a reconfigurar sus concepciones de género. Miren Llona (2000: 459) ha señalado que "la progresiva incorporación de las mujeres a distintas parcelas del ámbito público supuso una alteración de los límites que lo hacían inaccesible al sexo femenino". En el nacionalismo vasco convivieron la visión conservadora continuadora de la misoginia de Arana y una nueva corriente que, ocultando esta visión jerárquica tras la idea de la complementariedad entre los sexos, promovió el binarismo enfatizando la diferencia sexual. Se produjo entonces un proceso de incorporación de las mujeres al proyecto político nacionalista vasco "en calidad de mujeres y en posición subalterna" (Aresti, 2014: 291). Estos cambios de contexto y esta evolución en el seno del nacionalismo vasco se materializó también en una reinvención de la tradición cultural y folclórica vasca. Esta tradición sería así redefinida desde la combinación de operaciones de exclusión e incorporación sexuada.

A partir de la Primera Guerra Mundial se permitió, facilitó e incluso se aleccionó la participación de las mujeres en aquellas funciones que se consideraron propias de su género, a la vez que se denegó en las que quedan asignadas al masculino. La maternidad constituyó la función principal y necesaria de 
todas las mujeres sin excepción, se delimitó el marco de acción política para ellas a las actividades consideradas propias de su carácter maternal: como encargadas de roperos, en la beneficiencia y en la enseñanza del euskera fundamentalmente. En el ámbito de la danza, esto se materializó de dos maneras. En primer lugar el aurresku quedó definitivamente encasillado como danza masculina y por tanto, fuera del campo de acción de las mujeres si no era para interpretar el papel de invitadas u homenajeadas. En segundo lugar, se impulsaron y crearon en todo el país los grupos de poxpolinas (Araolaza, 2016), replicando el modelo de los ezpata-dantzariak, de forma que se trató de naturalizar a través de la danza la diferencia sexual, al asignarse a cada grupo vestuario, repertorio y estilo corporal que reproducían los estereotipos de género. Esta evolución fue vivida de forma contradictoria por las mujeres que participaron en el movimiento nacionalista vasco, pues a la vez que limitaba con rigidez su campo de acción, dignificaba la condición maternal. Ante esta delimitación de los marcos de acción en función del género, Polixene Trabudua, activa propagandista del nacionalismo vasco de la época aseguraba (Aresti, 2014: 301) que "lejos de producirle pena, esta diferencia le causaba plena emoción y alegría porque Dios le había concedido el más hermoso regalo, la maternidad".

El proceso de redefinición de las categorias y sus funciones no estuvo exento de tensiones. Tras la fundación de Emakume Abertzale Batza (EAB) en 1922, el dirigente nacionalista Elías Gallastegui animó a las mujeres a "implicarse en las labores de difusión del ideario y la emoción patrióticas" (Llona, 2000: 463), invitación a la que respondieron positivamente muchas de ellas. Superado un marco y en proceso de construcción del nuevo, el resultado, expuesto por Miren Llona (2000: 477) fue que forzaron "los límites del terreno de juego que imponía el nacionalismo, conquistaron nuevas parcelas de actividad para las mujeres y contribuyeron, de esa manera, a redefinir las barreras de género vigentes". El pastor Policarpo Larrañaga (1930), impulsor de grupos de poxpoliñas, animador y cronista de EAB, abordó la espinosa cuestión de la moralidad en la danza vasca. Su conclusión principal (1930: 75) coincide en parte con la que el Padre Larramendi propugnara siglo y medio antes: que se difundan los bailes autóctonos y se destierren "los inmorales bailes exóticos". Pero en consonancia con los nuevos tiempos, Larrañaga propone que se organicen "cuadros de dantzaris de ambos sexos."

Algunas mujeres exploraron los límites de las categoría de género que estaban en proceso de redefinición. La prensa nacionalista advertía (Aresti, 2014: 293) del riesgo que suponían "las extravagancias modernas que querían hacer desaparecer las diferencias entre hombres y mujeres" y las tachaba de "utopía opuesta a la realidad de la vida". Las impúdicas libertades de las modistillas 


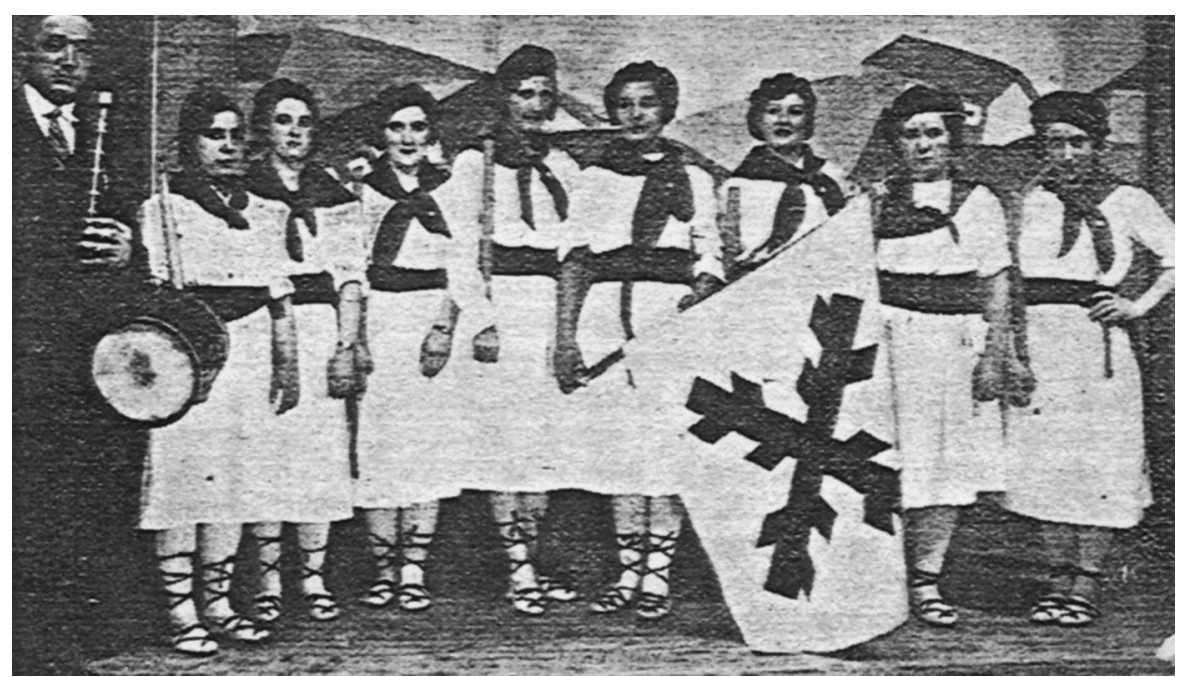

Grupo femenino de ezpata-dantzaris que se presentó en Bilbao el 15 de agosto de 1931. Fotografía publicada en la revista Txistulari, 23, 1931, pág. 9

(Aresti, 2017: 98) o los contemplativos paseos de las flaneuses (D’Souza \& McDonough, 2008) desafiaban las fronteras que se imponían a las idealizadas mujeres vascas. El Padre Donostia (1933: 6) se vio obligado a remarcar los límites del terreno en una conferencia que impartió en 1932 en Bilbao a los maestros y a las maestras de Ikastola-Batza: "Es indudable que las niñas no pueden bailar todas las danzas vascas. Por ejemplo, el Ezpata Dantza bizkaino y varios números del guipuzcoano no se han hecho para ellas". La referencia a la ezpata-dantza vizcaína no era casual. Unos meses antes, el 15 de agosto de 1931, un grupo de mujeres nacionalistas se había atrevido a formar el primer grupo de ezpata-dantza femenino y bailar en público. La novedosa imagen de las ocho ezpata-dantzaris posando con la bandera de la Cruz de San Andres se publicó en la revista Txistulari ${ }^{28}$. Acompañaba a la imagen una escueta nota, que trataba de interpretar el paso dado por las mujeres en clave de humor: "El primer grupo de ezpatadanza femenino. Las bilbotarras tienen muy buen humor; han celebrado la fiesta de su patrono con este cuadro de danzaris...". En diciembre de 1931, con ocasión de la fiesta de las modistillas el grupo de ezpata-dantzaris femenino volvió a actuar en Bilbao. Posiblemente fue su última actuación. Experiencias como aquélla son indicativas de las tensiones que acompañan la imposición de límites en razón del sexo. La inicia-

${ }^{28}$ El primer grupo de ezpatadanza femenino. (1931). Txistulari, (23), 9. 
tiva de las ezpata-dantzaris desafiaba tanto la operación de exclusión como la de radical feminización de la danza vasca.

Las siguientes palabras del Padre Donostia (1933: 2-8) pronunciadas pocos meses después de la actuación de las mujeres en la conferencia impartida en Bilbao a maestros y maestras nacionalistas condensan las ideas fundamentales que he tratado de discutir en el presente artículo. Es el relato de una comunidad imaginada que crea y recrea su tradición, utilizando para ello materiales escogidos de su legado e inventando nuevos cuando no se corresponden con los parametros políticos, morales y de género con los que ha confeccionado su narrativa:

"Al preconizar yo esta difusión de bailes de ellos y ellas, no solamente miro el problema desde un punto de vista de revasquización, sino también moral: en fin de cuentas, vasquización y moral son dos términos que no sólo no se repelen sino que se completan. [...] La canción y el baile vascos son los dos ejes artísticos sobre los que debe girar la enseñanza musical y plástica de la escuela. ¡Dichosos nosotros, los vascos, que no tenemos necesidad de rompernos la cabeza buscando material para estas disciplinas artísticas! Lo tenemos y en abundancia y de primera calidad... Y si no tuviéramos todo lo que para un caso particular deseamos, creémoslo... [...] ¿Quién nos impide a nosotros, vascos del siglo XX, crear cosas nuevas basándonos en la tradición recibida?.... Si el repertorio vasco de danza no fuese suficiente para las niñas, imaginemos algo propio para ellas... No es difícil conseguirlo."

José Gonzalo Zulaika Padre Donostia (Bilbao, 1932)

La auto-invitación a imaginar algo propio dio sus frutos. Imaginaron algo para ellas y lo llamaron naturaleza femenina, convirtiéndolo de esa manera en esencia inalterable. Tan inalterable como la tradición, que como hemos visto, nunca dejó de cambiar. En la primera parte del siglo XX los cambios políticos y sociales se acompañaron por diferentes visiones de género que tuvieron su reflejo en el nacionalismo vasco. Hemos observado cómo se reflejaron estas visiones y el proceso de cambio en la danza tradicional vasca, cómo se categorizó, explicó y adaptó en función de las ideas de identidad, nación, género y moralidad que se querían proyectar en ellas en cada momento, y cómo la creación de la tradición, y especificamente en este caso el de la principal danza nacional vasca, el aurres$k u$, se usó para naturalizar la diferencia sexual con la que fue imaginada.

\section{Bibliografía}

Albizu, I. (2017). Entreactos: ensayos de filosofia y danza. Madrid: Ediciones Cumbres. Altonaga, B. (2016). Mujeres viriles en el siglo XVIII: la construcción de la feminidad por el discurso foralista de Manuel de Larramendi. Historia contemporánea, (52), 9-42. 
Altuna, B. (2006). La idea de pureza moral y religiosa en el discurso identitario vasco. Cuadernos de Alzate, (34), 41-67.

Álvarez Cañibano, A. (2006). Documentar la danza. En Encuentros sobre documentación 2006 (pp. 133-166). Vitoria-Gasteiz: Artium.

Anderson, B. (2006). Imagined communities: reflections on the origin and spread of nationalism (Revised ed). London [etc.]: Verso.

Antequera Chávez, J. A. (2016). Una descripción del Aurresku a principios del siglo XX, por Manuel Díaz de Arcaya (I). Dantzariak, 61, 81-103.

Arana Goiri, S. de. (1897, julio 11). Efectos de la invasión. Baserritarra, pp. 1-3.

Arana Goiri, S. de. (1980a). Obras completas de Sabino Arana Goiri (vol. I) (2. argitaldaria Martin Ugalderen ardurapean, Vol. 1). Donostia: Sendoa.

Arana Goiri, S. de. (1980b). Obras completas de Sabino Arana Goiri (vol. II) (2. argitaldaria Martin Ugalderen ardurapean, Vol. 2). Donostia: Sendoa Argitaldaria.

Araolaza Arrieta, O. (2016). Las Poxpolinak: género y nacionalismo en la construcción del modelo de las bailarinas vascas. En La Investigación en danza en España 2016 (Vol. 2, pp. 179-185). Valencia: Mahali.

Aresti, N. (2006). Género e identidad en la sociedad del siglo XVII. Vasconia: Cuadernos de historia - geografía, (35), 49-62.

Aresti, N. (2014). De heroínas viriles a madres de la patria. Las mujeres y el nacionalismo vasco (1893-1937). Historia y Política, 31 (enero-junio), 281-308.

Aresti, N. (2016). El langile respetable: masculinidad, moral y trabajo en el nacionalismo vasco. En ¿La España invertebrada?: masculinidad y nación a comienzos del siglo XX (pp. 119-136). Comares.

Aresti, N. (2017). El «gentleman» y el bárbaro. Masculinidad y civilización en el nacionalismo vasco (1893-1937). Cuadernos de Historia Contemporánea. Dosier: Masculinidades, nación y civilización en la España contemporánea, 39, 83-103.

Azkue, Resurrección María de. (1922). Cancionero popular vasco (Ed. manual, sin acompañamiento). Barcelona: A. Boileau \& Bernasconi.

Azkue, Resurreción María de. (1922). Cancionero popular vasco / de Resurrección $M^{a}$ de Azkue (1990. ${ }^{a}$ ed.). Bilbo: Euskaltzaindia.

Bauman, R. (1992). Folklore. En Folklore, cultural performances, and popular entertainments: a communications-centered handbook (pp. 29-40). New York [etc.]: Oxford University Press.

Bell Stephens, E. (1837). The Basque provinces : their political state, scenery, and inhabitants ; with adventures amongst the Carlists and Christinos / by Edward Bell Stephens. (Vol. Vol. I.). London: Whittaker \& Co. Ave Maria Lane.

Berguices Jausoro, A. (2016, noviembre 14). Organología popular y sociabilidad: El baile de La Casilla de Abando-Bilbao y la expansión del acordeón en Bizkaia (1880-1923) (Doktore tesia). Euskal Herriko Unibertsitatea - Universidad del País Vasco, Biilbo.

Bidador, J. (2005). Dantzaren erreforma Euskal Herrian. Bilboko Udala, Kultura eta Euskara Saila. 
Butler, J. (1988). Performative Acts and Gender Constitution: An Essay in Phenomenology and Feminist Theory. Theatre Journal, 40(4), 519-531.

Butler, J. (2006). Gender trouble: feminism and the subversion of identity (Originally published: 1990). New York [etc.]: Routledge.

Castell, Á. M. (1897). El aurresku. Euskal-Erria: revista bascongada, 37(2o sem. 1897), 568-570.

Cavanilles, A. (1858). Lequeitio en 1857. Madrid: Martin Alegría.

Citro, S., \& Aschieri, P. (Eds.). (2012). Cuerpos en movimiento: antropología de y desde las danzas. Buenos Aires: Editorial Biblos.

dantzan.eus. (2016). Santurtzi 1921 Ohorezko aurreskua emakumeen eskutik. Santurtzi. Recuperado a partir de https://dantzan.eus/bideoak/santurtzi-1921-emakumeenaurreskua-soka-dantza

Díaz de Arcaya, M. (1906). La danza euskara ó aurresku. Hojas selectas, 49, 44-53.

Díaz Freire, J. J. (2001). El cuerpo de Aitor: emoción y discurso en la creación de la comunidad nacional vasca. Historia social, (40), 79-96.

Donostia, J. A. de. (1932). La Conferencia del Padre José Antonio Donostia. En el salón novedades de San Sebastián. Txistulari, 28(sept.-oct. 1932), 3-4.

Donostia, J. A. de. (1933). La Música en las Escuelas Vascas. Txistulari, (4 (Año VIEpoca 2. ${ }^{\text {a) }), ~ 2-8 . ~}$

Donostia, J. A. de. (1983). Obras completas del P. Donostia. (J. de Riezu, Ed.) (Vol. II). Bilbao: La Gran Enciclopedia Vasca.

D'Souza, A., \& McDonough, T. (Eds.). (2008). The invisible flâneuse? gender, public space, and visual culture in nineteenth-century Paris. Manchester: Manchester University Press.

Dueñas, E. X. (2016, febrero 23). Nesken aurreskuan bukatu zuten 1921eko estropadak. Recuperado 10 de enero de 2018, a partir de https://dantzan.eus/kidea/EXD/ nesken-aurreskuan-bukatu-zuten-estropadak

Dueñas, E. X. (2017). Unas regatas que finalizaron en Aurresku. «Breve» crónica de una película de 1921. Dantzariak, 62, 120-139.

Dueñas, E. X. (2018). Unas regatas que finalizaron en Aurresku. [Borrador de trabajo sin publicar].

Fischer, C. A. (1802). Travels in Spain in 1797 and 1798 / by Frederick Augustus Fischer; with an appendix on the method of travelling in that country. (Translated from the german). London: T.N. Longman and O. Rees.

Gascue, F. (1915). El Aurresku.

Gascue, F. (1916a). El aurresku en Guipúzcoa a fines del siglo XVIII según Iztueta. Imprenta de Martín, Mena y Ca,.

Gortazar, J. C. de. (1920). Bilbao a mediados del siglo XIX según un epistolario de la época / J.C. de Gortázar. Bilbao: Imprenta de la Biblioteca de Amigos del País.

Guezala, L. de. (s. f.). El pensamiento de Sabino Arana y Goiri a través de sus escritos.

Hanna, J. L. (1987). To Dance is Human: A Theory of Nonverbal Communication. University of Chicago Press. 
Hobsbawm, E., \& Ranger, T. (Eds.). (1983). The Invention of tradition. New York: Cambridge University Press.

Irigoien, I. (1985). La danza en el País Vasco. Bilbao: Caja de Ahorros Vizcaina.

Irigoien, I. (1996). El aurresku en Bilbao. Bidebarrieta: Revista de humanidades y ciencias sociales de Bilbao, 1, 335-345.

Irigoien, I. (2006). Las Fiestas de Bilbao: danzas y músicas entre los siglos XVI y XIX (I). Bidebarrieta: Revista de humanidades y ciencias sociales de Bilbao, (17), 335-486.

Irigoien, I. (2007). Andrazkoak Durangaldeko jai eta dantzetan. Astola, 1, 18-33.

Irigoien, I. (2010a). Lekeitio San Pedro eta San Juan Jaiak. Dantzariak, 56, 96-110.

Irigoien, I. (2010b). Soka-dantza de Mujeres [Entziklopedia online]. Recuperado 19 de enero de 2016, a partir de http://aunamendi.eusko-ikaskuntza.eus/es/soka-dantzade-mujeres/ar-152200/

Izarra Retana, J. de. (1921). Crónica de Estíbaliz, 158.

Iztueta Echeverría, J. I. de. (1824). Guipuzcoaco dantza gogoangarrien condaira edo historia beren soñu zar, eta itz neurtu edo versoaquin : baita berac ongui dantzatzeco iracaste edo instruccioac ere ... beraren eguillea Juan Ignacio de Iztueta. Donostia: Ignacio Ramón Baroja-ren Moldizteguian.

Lande, L. L. (1931). Tres meses de viaje en el País Vasco: (1877). Revista Internacional de los Estudios Vascos (RIEV), 22, 82-115.

Larramendi, M. de. (1985). Corografía de la provincia de Guipúzcoa. Echévarri: Amigos del Libro Vasco.

Larrañaga, P. de. (1930). La moral vasca: moralidad y costumbres vascas. Bilbao: Escuelas Gráf. de la Santa Casa de Misericordia.

Larrinaga Zugadi, J. (2004). Mujeres y Soka dantza. Euskonews \& Media, 268. Recuperado a partir de http://www.euskonews.com/0268zbk/gaia26804es.html

Larronde, J.-C. (1998). Manuel de Ynchausti (1900-1961): etorri handiko mezenas bat = un mecenas inspirado. Villefranque: Bidasoa, Institut d'Histoire Contemporaine.

Legarreta, X. (2008). Bermeo $:$ Herri baten aldiunean = Instantes de un pueblo. Editorial Iparraguirre S.A.

Llona González, M. (2000). Polixene Trabudua, historia de vida de una dirigente del nacionalismo vasco en la Vizcaya de los años treinta. Historia Contemporánea, $0(21)$, 459-484.

Manuel Alfonso Acuña. (1916, abril 20). Cartas a un amigo desde Madrid. La Unión ilustrada, 5-6.

Maquieira, V. (1998). Cultura y derechos humanos de las mujeres. En P. Pérez Cantó (Ed.), Las mujeres del Caribe en el umbral del 2000 (pp. 171-203). Madrid: Dirección General de la Mujer/Consejería de Sanidad y Servicios Sociales/CAM.

Merton, R. K. (1995). Teoría y estructura sociales. México: Fondo de Cultura Económica.

Nordera, M. (2011). Ser bailarina en el siglo XVIII: el cuerpo femenino entre la sociedad y la escena. En B. Martínez del Fresno (Ed.), Coreografiar la historia europea: cuerpo, política, identidad y género en la danza (pp. 116-137). Oviedo: Universidad de Oviedo. 
Peyron, J. F. (1782). Nouveau voyage en Espagne, fait en 1777 \& 1778 : dans lequel traite des Moeurs, du Caractere, des Monumens anciens $\&$ modernes, du Commerce, du Théatre, de la Législation des Tribunaux particuliers à ce Royaume, E de l'Inquisition; avec de nouveaux détails sur son état actuel, E sur une Procédure récente E fameuse. (Vol. II). Londres: chez P. Elmsly.

Pontremoli, A. (2011). Coreografiar la gloria: danza y allegrezze en las entradas reales de Milán (1598-1599). En B. Martínez del Fresno (Ed.), Coreografiar la historia europea: cuerpo, política, identidad y género en la danza (pp. 39-70).

Reed, S. A. (2010). Dance and the nation: performance, ritual, and politics in Sri Lanka. Madison, Wis: University of Wisconsin Press.

Reed, S. A. (2012). La política y la poética de la danza*. En S. Citro \& P. Aschieri (Eds.), S. Benza (Trad.), Cuerpos en movimiento: antropología de y desde las danzas (Publicado en Annual Review of Anthropology, vols. 27, 1998, pp. 503-532. Traducción: Silvia Benza. Revisión: Silvia Citro., pp. 75-100). Buenos Aires: Editorial Biblos.

Rojo, F. (1999). Emakumea euskal dantza tradizionalean. Euskonews \& Media, 18. Recuperado a partir de http://www.euskonews.com/0018zbk/gaial804eu.html

San Sebastián, M. (2008). Antropología de la danza: el caso de Ataun. Jentilbaratz: cuadernos de folklore, 11, 81-109.

Sánchez Ekiza, K. (2005). Txuntxuneroak: narrativas, identidades e ideologías en la historia de los txistularis. Tafalla: Altaffaylla.

Santoyo, J.-C. (Ed.). (1978). Viajeros ingleses del s. XIX. (R. M. Sillaurren \& J. M. Santamaría, Trads.). Vitoria: Caja de Ahorros Municipal de Vitoria.

Schechner, R. (1990). Wayang Kulit in the Colonial Margin. TDR (1988-), 34(2), 2561. https://doi.org/10.2307/1146026

Tortajada, M. (2004). Mujeres-diosas: las ballerinas románticas. Casa del tiempo, 97, 45-53.

Zamacola, J. A. de. (1818). Historia de las naciones bascas de una y otra parte del Pirineo septentrional y costas del mar Cantabrico, desde sus primeros pobladores hasta nuestros dias, con la descripcion, caracter, fueros, usos, costumbres y leyes de cada uno de los estados bascos que hoy existen (Vol. III). Auch: Imprenta de la Viuda de Duprat. 